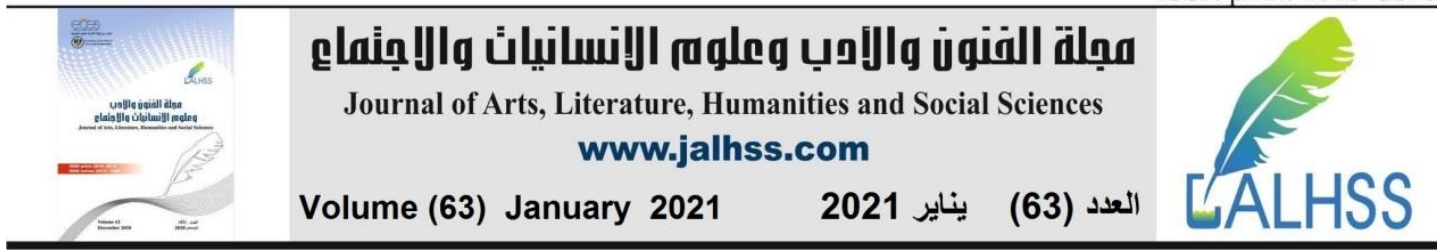

\title{
Connecting with Readers Through Conversational Style with Reference to Maya Angelou's Letter to My Daughter
}

\author{
Nouf Alkhattabi \\ English Department - College of Languages and Translation \\ University of Jeddah - Kingdom of Saudi Arabia \\ Email: naalkhtabi@uj.edu.sa
}

\begin{abstract}
The style of literary writing is one of the major aspects that urge readers to pick out their works. Some famous contemporary writers have adapted conversational style. When their messages are carried out in conversational style, they are seen as partners in conversation with the readers. As a result, a strong connection is built among them and the message is easily conveyed. The study here, examines the impact of conversational style in literary works with reference to Maya Angelou's Letter to My Daughter. Through applying such style, the author exposes her personal thoughts and feelings to audience of different levels. The study also examines the different techniques used to effectively change from formal to conversational tone in literary works to go beyond the limit of sentences and words. It also emphasizes that such a style invites readers, but the authors must be careful to be sincere and not to lose their credibility. The researcher suggests that further studies of conversational style should be executed especially, with the vast spread of social media.
\end{abstract}

Keywords: Conversational Style, Maya Angelou, Letter to My Daughter. 


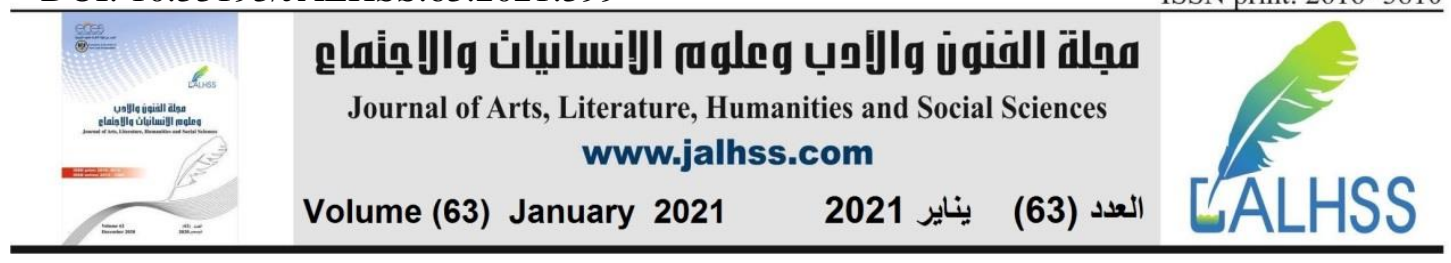

One of the most effective ways through which authors can connect with their readers is through adopting the conversational style of writing. The style is intended to engage readers, creating a connection with writers more effectively than formal approaches. Traditionally, writers have used stylistic choices that determine the level of formality and connection with readers. For example, an author can use a narrative essay to connect with readers because of its conversational and engaging style. A narrative essay typically includes personal stories and is usually written from a first-person point of view, giving it a more conversational tone. First-person perspective gives an essay a more personal feel as opposed to the more distanced third-person account. The author's choice of words significantly affects the effectiveness of his or her conversational style. Simple words are useful, especially when the writer wants to create a conversational style and speak directly to the audience. Colloquial phrases, which are never used in formal essays, are applicable to great effect in a narrative and conversational essay. Most importantly, a conversational approach transcends any disconnect between writers and readers because it feels more immediate and personal and speaks directly to readers instead of the audience at large.

Throughout history, authors have used conversational styles to connect with readers in ways that formal writers have failed to do. Since the turn of the $20^{\text {th }}$ century, the nature and relationship between spoken and written language has attracted considerable attention among linguists. While most of the $20^{\text {th }}$ century linguists focused on either oral or written language, those interested in the structure and approach centered on the exclusion of writing. In the preceding century, scholars regarded conversational style of writing as the true form of authors-readers interactions and so, the approach to conversational style of writing has continued to change drastically. Woolbert was one of the early scholars to explore the similarities and differences between formal and conversational writing. He observed that "speaking and writing are alike - and different; just how like and how different has never been adequately stated" (1927, p.271). Woolbert's study on conversational writings presented only a number of very limited general observations in which "the voice of the speaker can always reveal more than the page - or else less" (1927, p.284).

Many of the early studies on conversational style of writing served as an important motivation for further research on the field. For example, German scholars such as Grimm had recorded and studied speech, while some British linguists developed phonetics to create more connection between writers and readers. All the while, educational psychologists and discourse analysts felt justified demonstrating the need to include conversational style of writing to temper the more official approach. According to Bernstein, the "restrictive" formal language confounded children in their transition to literacy, thus the need to "placate their quest for knowledge by using a personal approach to writing" (1990, p.120). Consequently, there was a growing need for authors to adopt a friendly way of encouraging children to gain knowledge using a relatable linguistic approach. 


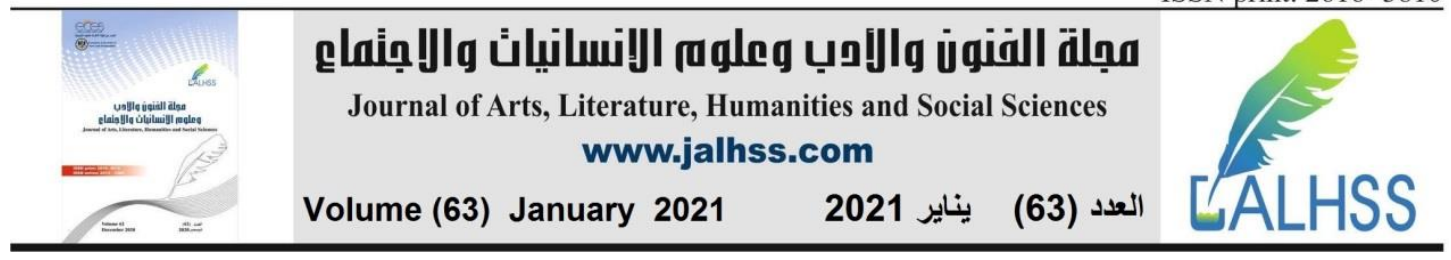

The 1960s was a period in which authors began to incorporate creativity in their writing on a much wider scale. Creative writing designs that appealed to a wide range of readers resulted in interesting results. For example, Drieman drew up an exemplary methodology for the study of conversational writing, which largely involved considerable textual variation and application of general principles for the collection of spoken and written data. Drieman focused on text analysis, advising for variation of texts to conform to readers' needs (1962, p.39). The scholar further conducted various research studies to highlight the importance of conversational approach to writing in training. Results indicated that the more the conversational tone, the more the rate of comprehension of text. Some of the earliest studies used word frequency counts as one of the primary ways of distinguishing between formal and informal writing. Early authors began by investigating conversational written text without systematically correlating the findings. For example, Horn and Ward computed a lexicon of about ten thousand words, which were most commonly used in writing and noted that the authors used different styles of writing to connect to readers (2004, p.193). Other linguistic scholars have made efforts to distinguish differences in patterns of linguistic behaviors, while attempting to establish the best methods for authors and speakers to connect with readers and audiences respectively.

The current study is an attempt to survey some of the results of previous studies and the input of influential writers touching upon the topic of conversational writing. It highlights the importance of conversational approach of writing, especially when writers want to effectively connect with their readers. Authors will understand the importance of writing in styles that facilitate connection with a wide range of readers by remaining relevant to their audience. They will learn about the identity of their audience in order to determine the key areas of focus. As a result, readers will gain the ability to identify the various writing styles that authors use to articulate textual message.

Consequently, the model of conversational writing style even transforms the technical skills of reference and citation for readers. When students are asked to write purely from their selves, they struggle to create a real connection with readers. In other words, they find themselves limited by their own thinking and writing. As a result, they are only able to write within the heavily literate formal contexts of their college and professional life. If students do not learn the importance of conversational approach to writing, they may become "parrots of authority" or raconteurs stocked with formal anecdote for every occasion (Ballenger, 2009, p.22). Thus, the overarching objective of this study is to introduce learners to the community of the literate on their own.

The researcher will use qualitative approach to establish various ways in which authors use conversational styles to connect with readers. According to Ballenger, using qualitative methods has proved to be appropriate in topics that deal with deeper understanding of human behavior and language (2009, p.13). The research examines how and why certain linguistic phenomena occur, and how human behavior influences language use. Many linguistic studies have involved the analysis of people's behaviors during their interactional relationships. In such studies, 


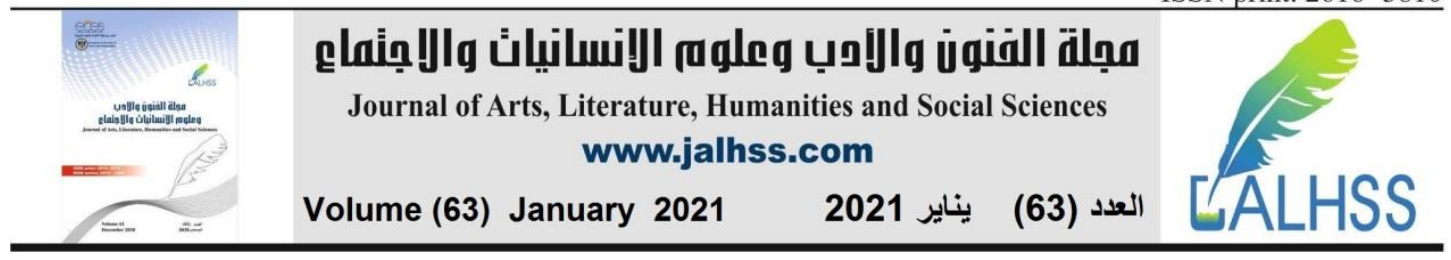

qualitative methods are often found to be the most appropriate when used in the research.

The researcher will review Maya Angelou's 2008 book Letter to My Daughter, which will serve as the primary reference in the study, not least because of her use of conversational style and ability to incorporate a brand of writing that makes her work highly appealing to a wide readership. Notably, Angelou's book is a collection of twenty-eight essays, which include poems and commencement addresses, and is primarily dedicated to her daughter, who is a symbolic presenter of all women. Because of the interpersonal style of writing, Angelou's book is a perfect basis for conducting any research relating to conversational approach to writing. Besides, the book has been recognized by many scholars as full of the author's wisdom. Therefore, the researcher will establish the extent to which the book has inspired a generation of authors to adopt conversational approach in their writing.

Writing in conversational style can be very interesting. Yet, authors find it difficult to avoid the formal writing styles they were taught in school. According to Bazerman, writers need to have the ability to transform their thoughts into written words without changing the original meaning and context (1980, p.664). By establishing the importance of the author's voice and the authority of personal perception, linguists have been able to give weight to what students and authors want to express in their work. They need to be conscious of the importance of conveying the underlying message to readers through conversational tone. However, a closer observation of the individual writer dilemma has led to the notion that conversational style is grounded on experience, native thought, and personal motivation to communicate (Tannen, 1982, p.2). Conversational communication and writing targets certain audience leading to a greater understanding between the communicators and the recipients. Moreover, conversational writing requires the deep understanding of what writers mean in their text while taking into consideration how earlier comments relate to the responder's thoughts.

The immediacy of conversational texts differs significantly from the reflectiveness of formal writing. While the latter includes a high level of complexity and ambiguity, the former can simply be taken at face value. Ballenger, states, "the transition between formal to conversational style of writing requires a great deal of patience and commitment" (2009, p.22). Consequently, modern authors who are able to communicate using a conversational model play an important role in connecting with their readers. According to Bazerman, an effective conversational style of writing motivates readers to explore their own assumption and framework of thought (1980, p.659). At first, readers' reaction to conversational text may be ununiformed, either fending off new and unfamiliar material, or comply totally to the "the authority of the written word" (Bazerman, 1980, p.659). However, with time, they are able to articulate their changing responses and become more comfortable with conversational texts.

Developing reactions should be one of the key responsibilities of conversational writers. According to Tannen, it is important for writers to have the ability of measuring what a book or article actually accomplished compared to its 


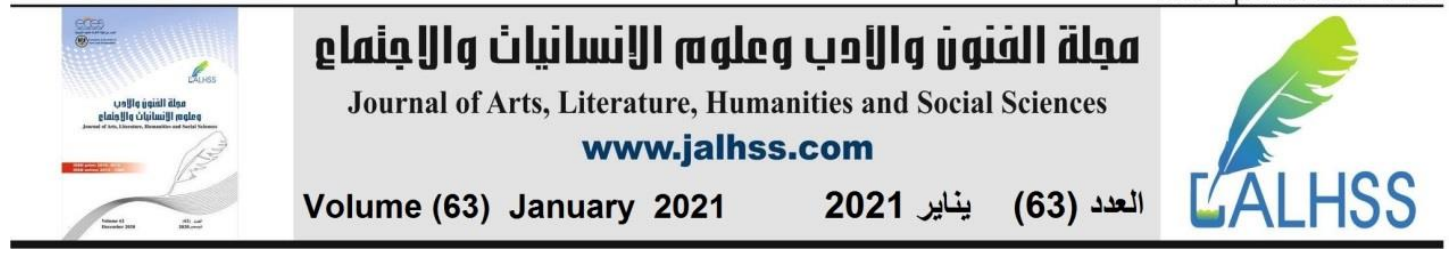

stated objectives (1982, p.22). Conversational texts are designed to bring the readers closer to the authors. Therefore, the readers' reaction to a book is one of the most effective ways of evaluating whether it has accomplished the authors' objectives. Another kind of evaluation is measuring the author's assumption against the reader's reality by comparing data from readers' prior experience, new observations, or through technical experiments (Toolan, 2010, p.320). In these kind of exercises, readers of conversational texts must judge whether there is agreement or disagreement between the contents of the book and their anticipations.

Maya Angelou was one of the contemporary authors who have used a conversational approach to writing with the aim of establishing a close relationship with readers. Dedicated to the daughter she never had, Letter to My Daughter transcends genres and literary categories in terms of its connection to the readers. The author writes the book in an easy-going style and essentially puts the reader into the story. In fact, Angelou gives the impression that she is speaking directly to her readers rather than having them read about her thoughts. As a result, she can interact with them, despite the fact that most have never seen the author in real-life.

The intention of authors to connect with their readers through a conversational style of writing is often evident from the start. Angelou begins her book with an emotional statement, saying, "I gave birth to one child, a son, but I have thousands of daughters" (2008, p.xii). According to Sever, the first step to making one's writing sound more conversational than formal is to make it appear as if it is directed to a single reader rather than a group of people (2014, p.147). Angelou uses the firstperson narrative, which signifies the fact that she is speaking directly to the readers. Throughout her book, she uses the first-person narrative style to convey her underlying message on various social issues such as racism, segregation, and empowerment. Angelou creates the impression that she is speaking to people from all race and occupations. For example, she says "you are fat and thin and pretty plain, ... , educated and unlettered, and I am speaking to you all. Here is my offering to you" (2008, p.xii). Her sentiments echo across a wide range of readers because it appeals to their personal rather than collective consciousness.

Texts written in conversational style tend to address the collective rather than a selected group of readers. Writers can connect with a wide range of readers by essentially becoming storytellers. When people talk with their friends, they share personal stories and experiences in an intimate manner. Similarly, writers can easily connect with readers by including personal stories and experience in their work. The incorporation of personal stories helps inject human element in the text, which is highly valued in our digital age. Angelou prominently incorporates personal experience in her collection of essays Letter to My Daughter, enabling most readers to identify with her predicament. For example, she reveals that she only "gave birth to one child, a son", touching upon her anguish at never having daughters (2008, p.xii). The story telling approach helps her to effortlessly connect with readers, many of whom may identify with her inability to bear daughters. Most important, she captures their attention, making them eager to know about her thoughts of having an imaginary 


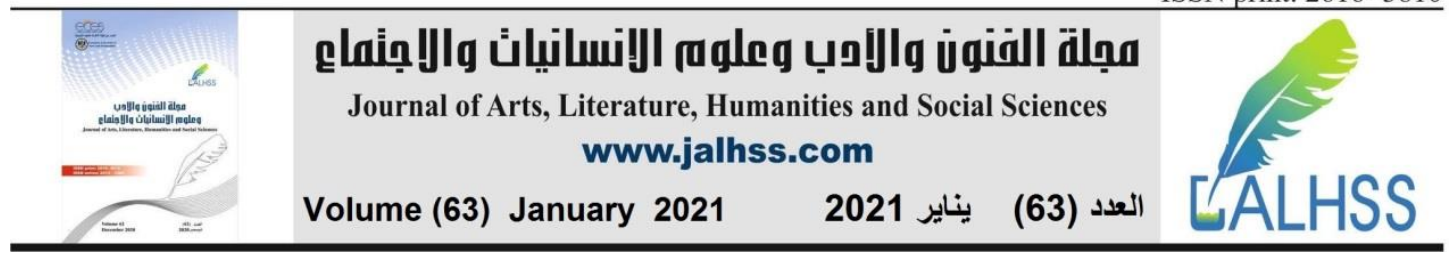

daughter. Angelou's story-telling instincts are further exemplified by the fact that she is able to put her wishes and fantasies in words, making her work entertaining.

Moreover, sharing personal stories in writing helps authors not only to connect with readers but also to demonstrate that there is a human element behind their narrative. When writers use stories, they must ensure that they focus on a theme that elevates the narrative from just being personal. According to Young, a universal and uplifting theme will make the text relevant to a wide range of readers (1995, p.16). In other words, the theme must relate to readers as much as it does for the authors themselves. In Letter to My Daughter, Angelou incorporates powerful themes that relate to social values such as family, equality, class and individual struggles. Moreover, the book reveals Angelou's path to leading a life of accomplishment despite the challenges she faced in her hostile environment.

Readers want to have the impression that they are reading relevant events as experienced by the authors themselves. To accomplish this goal, writers using conversational approach must always be "in touch with reality" (Young,1995, p.18). In her book, Letter to My Daughter, Angelou offers glimpses of her life that led her to become a literary icon. Through it, she teaches her readers critical lessons in compassion and fortitude, including how her insuperable grandmother in the highly segregated Arkansas brought her up. Most importantly, her story telling comes to the fore when she narrates about her experience in a sexless marriage that paradoxically left her with what she regards as the greatest gift of her life, her son. "I never had to spend one minute regretting giving birth to a child who had a devoted family, led by a fearless, doting and glorious grandmother. So I became proud of myself" (2008, p.25). If Angelou has told her story in a third-person and detached narrative style, it would not have the same endearment to readers. Instead, she uses the conversational approach, which seems to have warn readers about the reality of the world.

Authors who want to connect with their readers tend to use well-thought words to write the texts (Leonard, 2001). They put much effort to make sentences as simple and clear as possible by their choice of words. For example, they write directly in ways that appeal to general readership instead of padding their sentences with complex words and phrases, in his six rules of writing conversational text, Hakim observes:

"Never use a long word where a short one will do. If it is possible to cut a word out, always cut it out. Never use a foreign phrase, a scientific word or a jargon word if you can think of an everyday English equivalent" (2010)

In addition, depending on the audience, authors can use popular or generally acceptable slang to make their text engaging. However, such terms and phrases must be used moderately to minimize potential confusion on the part of readers. In Letter to My Daughter, Angelou uses expressive terms that underscore not only her own predicaments but also those of readers. Her choice of words helps to effortlessly and effectively convey her message to the readers. For example, to underpin the virtue of selflessness, Angelou uses simple sentences such as "A friend may be waiting behind a stranger's face" and "the human heart, which tells us all that we are more alike than we are unalike" (2008, p.75\&80). These sentences may appear simple from a formal 


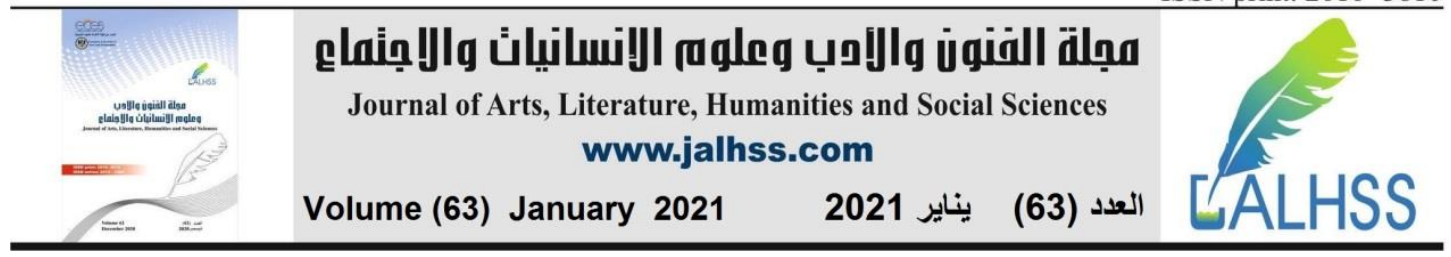

perspective, but they go a long way in helping the author to connect emotionally with her readers.

An important rule for using conversational writing style is to try to write to a single reader. To achieve this aim, sentences must appear personalized rather than general, making readers take ownership of the text. In other words, authors must think about the composition of their readers, including hopes, fears, struggles, and culture. On adopting a conversational tone that connects with readers, Steinbeck observes that "I have found that sometimes, it helps to pick out one person - a real person you know, or an imagined person and write to that one" (1988, p.48). In Letter to My Daughter, Angelou typifies an author who is familiar with her readers' circumstances. She speaks to a wide range of people from different economic classes and race. Her simple and emotional way of writing is indicative of the experience of the collective rather than the elite as her universal wisdom transcends social classes. For example, she observes,

"The ship of my life may or may not be sailing on a calm and amiable seas. The challenging days of my existence may or may not be bright and promising. Stormy or sunny days, glorious or lonely nights, I maintain an attitude of gratitude. If I insist on being pessimistic, there is always tomorrow. Today I am blessed" (2008, p.67).

These sentiments reflect the author's philosophy that people can choose not to be reduced by their misfortunes.

Conversational writing style is highly effective when authors are seeking to convey some sort of inspirational message. In unequal societies, the defeated are constantly seeking relief and means to improve their own welfare. Such individuals need a message of hope and an assurance that they can improve their own lot through commitment. Angelou's Letters to My Daughter illustrates the high level of oppression practiced against minority groups. Therefore, it becomes easy for the writer to tailor her message in ways that appeal to the minority groups such as blacks. In chapter one of her book, Angelou highlights the African Americans struggle with depression in a white dominant society. She regarded depression as difficult for everyone, especially for "single black woman in the Southern states tending her crippled adult son and raising two small grand-children" (2008, p.165). Consequently, many black readers will instantly connect with the author because of her fearless and direct approach to issues affecting minority groups.

Researchers have established that authors can enhance conversational style effective by injecting personality into the text. Novelist Elmore Leonard underscored the importance of personality, saying, "If it sounds like writing, I rewrite it" (2001, p.22). Injecting one's personality into writing has been a rule of many contemporary authors who want to connect with their readers. According to Horn and Ward, authors of conversational text should form the habit of reading their work loud to assess if the sentences sound unnatural and stilted (2004, p.30). Hence, authors need to ensure that they apply words they would ordinarily use when interacting with their friends and identify instances when it would be appropriate to use humor or drop some cultural references. As an African American who has faced segregation, Angelou is able to 


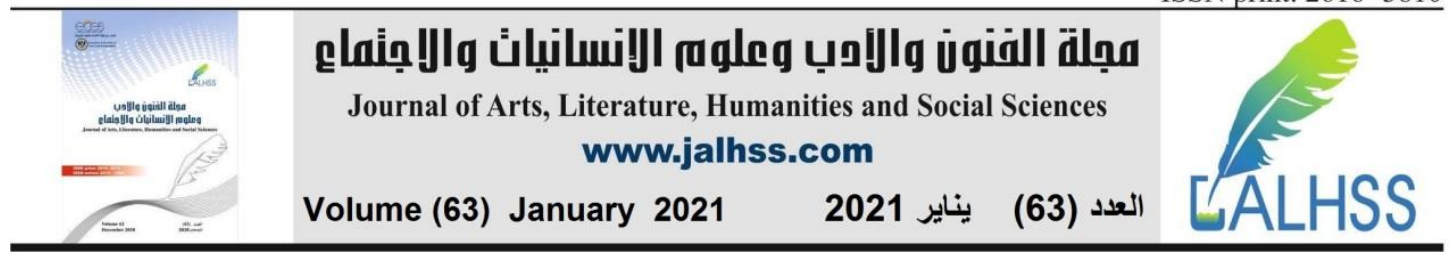

assert her authority, talking out of experience to reach out to her audience. Drawing on her own experience, she advises minority groups to rise above their challenges, saying:

"You may not control all the events that happen to you, but you can decide not to be reduced by them. Try to be a rainbow in someone's cloud. Do not complain. Make every effort to change things you do not like. If you cannot make a change, change the way you have been thinking. You might find a new solution" (2008, p.xii).

The author speaks these words with much confidence because she has experienced discrimination and is a member of the minority. For most people of African American descent, Angelou is speaking directly to them while inspiring them to achieve high ideals of life, despite their limitations. Her autobiographical narrative is not only captivating for readers but also informative and inspirational. Thus, she effortlessly connects with her readers through the simple act of appealing to their own experience and environments.

It is important that authors demonstrate authority in their work by using a specific style that readers can identify with. Complex texts are intimidating to read, thus, using paragraphs that are no more than three to four sentences long is one of the most effective ways of incorporating authority into a text. According to Horowitz and Berkowitz, writers who can successfully incorporate their spoken speech into words are highly appealing because they speak directly to readers (1964, p.130). Writing in short personalized paragraphs is similar to engaging in a friendly face-to-face dialogue. In contrast, using lengthy and complex phrases amounts to issuing a long speech, which makes the audience lose interest. Instead of using complex approach like many of her contemporaries, Angelou adopts brevity and conciseness, thus enabling her to communicate with readers of different intellectual levels. Even nonEnglish speaking readers are able to understand her text because of its simplified nature. Notably, she is not presumptive in her usage of words, and takes trouble in explaining even the most seemingly common terms. For example, she says, "One of my earliest memories of my grandmother, who was called 'Mamma', is a glimpse of that tall, cinnamon-colored woman with a deep, soft voice, standing thousands of feet up in the air with nothing visible beneath her" (2008, p.165). She does not presume that readers will know that her grandmother was called "mamma", although it is a common reference among many African American communities.

Many writers would greatly benefit from using conversational style when trying to appeal to their audience. Because of its fun and adventurous element, a conversational style of writing seems to be more fluid and can convey just about any message to the targeted audience. Vonnegut, one of the writing experts, observes that "The writing style which is most natural for you is bound to echo the speech you heard when a child" (1980, p.122). Consequently, writing in a conversational way should represent a lot of fun for the author. However, it is often a challenge to unlearn the formal ways of writing that one learns in school. Many authors only need to draw on their experience to translate their thoughts into words and speak directly to their readers through incorporation of humor and other relevant stories in their work. In her 


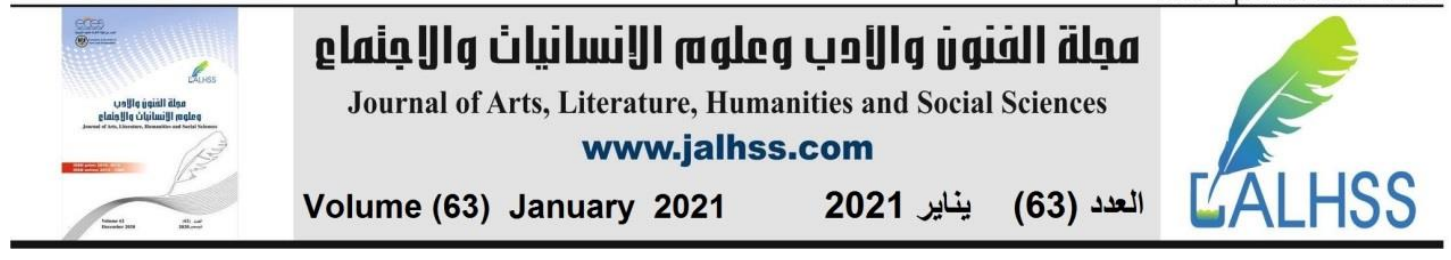

book, Maya Angelou seems to derive considerable fun from her work as she tells her captivating narrative about growing up in Arkansas and overcoming various challenges to become one of the most accomplished African American writers of all time.

In most instances, a conversational writing style seemingly breaks all conventional grammatical rules. For example, sentences can begin with pronouns and ends with verbs, and vice versa. Sometimes, sentences can be fragmented in an attempt by authors to infuse personal thoughts. In Letters to My Daughter, various informal grammatical styles are used in order to make the text enjoyable to read. The author prominently uses contradictory phrases aimed to entertain and educate readers in equal measure. For example, she suggests that people who get married never grow up as much as they become old (2008, p.6). By using such unconventional phrases, Angelou teaches readers about the importance of living a balanced life and making the most out of their existence.

Based on the existing research and the analysis of Maya Angelou's book Letters to My Daughter, it is evident that writers use different approaches to make their work conversational and connect with readers. It is clear that authors will sometimes need to use complex words to communicate a more precise meaning or deliver the message without losing its context. However, various prominent authors and scholars, including Maya Angelou, Kurt Vonnegut, and John Steinbeck, have demonstrated that one can use simpler words as a basis of their writing and only use complex words and phrases only when it is necessary. Contrary to formal texts, conversational writing requires authors to become far more personal. By using firstperson words, such as "I" and "you" they are able to build a connection with readers. It is also clear that the length of the sentences and words tend to affect the ease with which readers understand articles. Therefore, it is imperative for authors to keep their sentences short and simplify long phrases. Most importantly, using words with fewer syllables increase readability and enhance conversational value of a book. However, it is important for authors to ensure that they do not undermine the original message or theme of the subject matter. The findings from the expansive research further indicates that stories and personal narratives naturally compel human beings as they appeal to the emotions and engage sensory triggers among readers. Therefore, authors who are able to turn their data into stories will notice a greater interaction between themselves and their readers.

The researcher suggests a further study on the importance of adopting conversational style by authors and its urgency, especially nowadays. With the spread of social media and the increasing effect of its terms and language on the upcoming generation, authors must attempt to draw audience through conversational style of writing. Unfortunately, many writers lack the necessary knowledge on how to write in a conversational tone because of lack of adequate early training from their English teachers. Thus, the researcher highly recommends giving this issue much consideration and further study. 


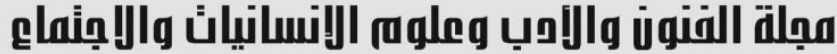

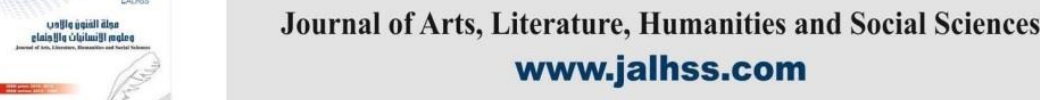

Journal of Arts, Literature, Humanities a
www.jalhss.com

Volume (63) January 2021

العدد (63) يناير 2021

\section{References}

1. Angelou, Maya. (2008). Letter to My daughter. New York: Random House, Inc.

2. Ballenger, Bruce. (2009).The curious researcher: A guide to writing research papers. New York: Longman.

3. Bazerman, Charles. (1980). "A Relationship Between Reading and Writing: The Conversational Model." College English, 41(6), pp. 656-661.

4. Bernstein, Basil. (1990). Class, Codes and Control: Vol 4: The Structure of Pedagogical Discourse. London: Routledge.

5. Drieman, Gerard HJ. (19620. "Differences between written and spoken language: An exploratory study." Acta Psychologica, 20, pp. 36-57.

6. Grimm, Jacob. (1984). On the origin of language. New York: Brill Archive.

7. Hakim, Joy. (2010). All the People: Since 1945 (A History of Us). Oxford University Press.

8. Horn, Laurence R., and Gregory L. Ward, eds. (2004). The handbook of pragmatics. Oxford: Blackwell.

9. Horowitz, Milton W., and Alan Berkowitz. (1964). "Structural advantage of the mechanism of spoken expression as a factor in differences in spoken and written expression." Perceptual and motor skills, 19(2), pp. 619-625.

10. Leonard, Elmore. (2001). "Writers on writing: Easy on the adverbs, exclamation points, and especially hooptedoodle." New York Times, pp. E1. Retrieved July 22, 2020, from https://www.nytimes.com/2001/07/16/arts/writers-writing-easy-adverbsexclamation-points-especially-hooptedoodle.html

11. Sever, Tuba. (2013). "Conversational Style: Analyzing Talk among Friends." ELT Research Journal, 2(3), pp.146-149.

12. Steinbeck, John. (1988). Conversations with John Steinbeck. Edited by Thomas Fensch. Jackson: Univ. Press of Mississippi.

13. Tannen, Deborah. (1982). "Oral and literate strategies in spoken and written narratives." Language, 58(1), pp. 1-21. 


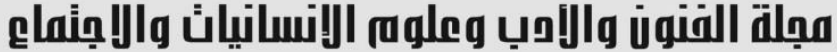

Journal of Arts, Literature, Humanities and Social Sciences

www.jalhss.com

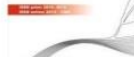

Volume (63) January 2021

2021

(63) (العدد ) (20)

14. Toolan, Michael. (2010). "The intrinsic importance of sentence type and clause type to narrative effect: or, how Alice Munro's "Circle of Prayer" gets started." Language and style. In honour of Mick Short. Edited by Dan Mclntyre and Beatrix Busse. Palgrave Macmillan, pp. 311-327.

15. Vonnegut, Kurt. (1980). How to write with style. New York: International Paper Company. Retrieved September 12, 2020, from https://www.openculture.com/2014/11/kurt-vonnegut-explains-how-t--write-withstyle-html

16. Woolbert, Charles Henry. (1927). The Fundamentals of Speech: A Text Book of Delivery, with a Section on Speech Composition and Interpretative Reading. New York \&London: Harper \& Bros.

17. Young, Richard. (1995). "Conversational styles in language proficiency interviews." Language Learning, 45(1), pp. 3-42. 